\title{
$1 \quad$ MRI and MRS on preserved samples as a tool in fish \\ 2 ecology
}

3

4 5

6 Pleuragramma antarctica, lipids

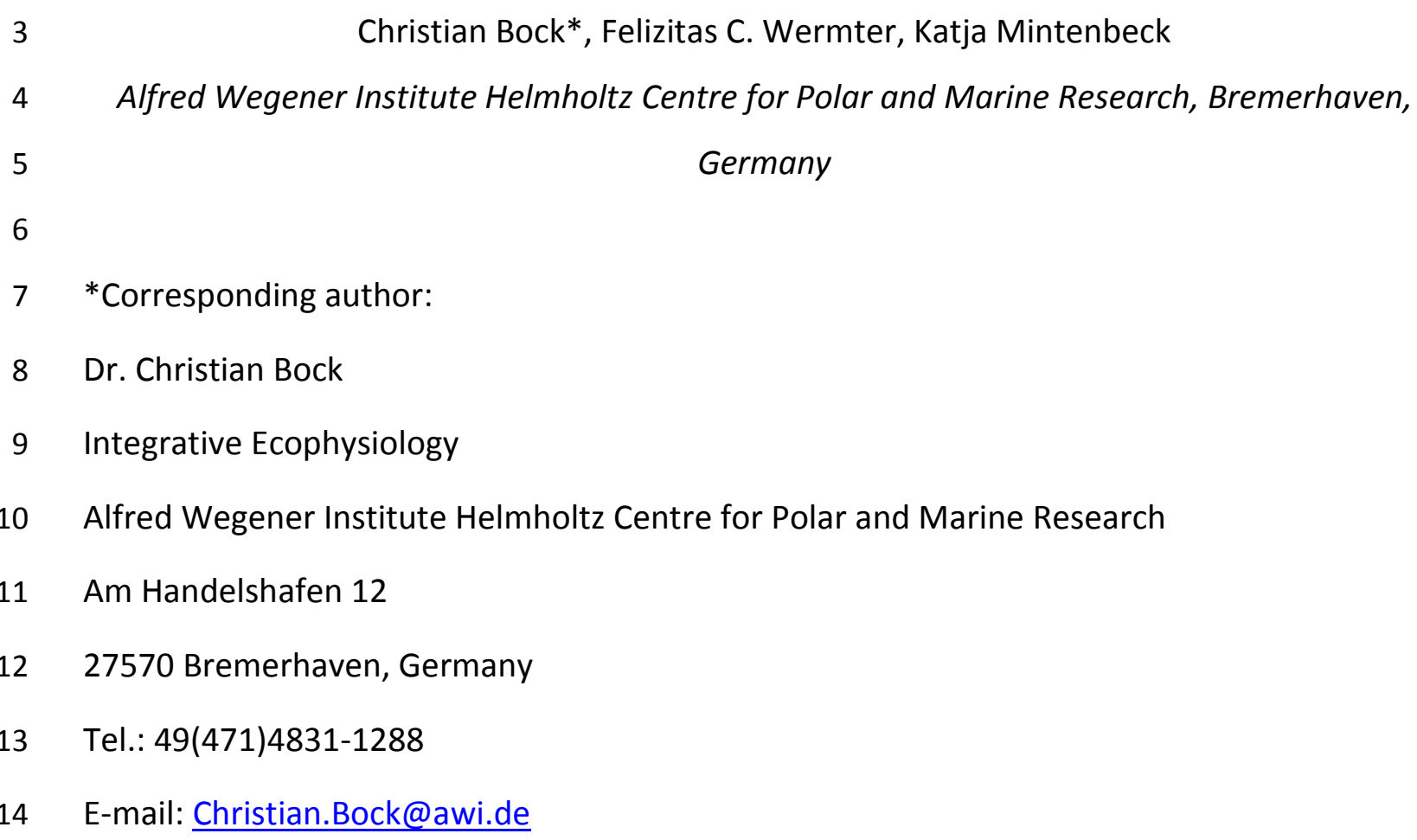

$7 \quad{ }^{*}$ Corresponding author:

8 Dr. Christian Bock

$9 \quad$ Integrative Ecophysiology

Keywords: Magnetic resonance imaging, NMR spectroscopy, preserved samples, formalin,

Short Title: MRI and MRS as tools in fish ecology 
20

21

22

\section{Abstract}

Magnetic Resonance Imaging (MRI) and Magnetic Resonance Spectroscopy (MRS) gain increasing attention and importance as a tool in marine ecology. So far, studies were largely limited to morphological studies, e.g. for the creation of digital libraries. Here, the utility of MRI and MRS for ecologists is tested and exemplified using formalin preserved samples of the Antarctic silverfish, Pleuragramma antarctica. As this species lacks a swim bladder, buoyancy is attained by the deposition of large amounts of lipids that are mainly stored in subcutaneous and intermuscular lipid sacs. In this study MRI and MRS are not only used to study internal morphology, but additionally to investigate functional morphology and to measure parameters of high ecological interest. The data are compared with literature data obtained by means of traditional ecological methods.

The results from this study show that MR scans are not only an alternative to histological sections (as shown before), but even allow the visualization of particular features in delicate soft tissues, such as Pleuragramma's lipid sacs. 3D rendering techniques proved to be a useful tool to study organ volumes and lipid content, which usually requires laborious chemical lipid extraction and analysis. Moreover, the application of MRS even allows for an analysis of lipids and fatty acids within lipid sacs, which wouldn't be possible using destructive methods. MRI and MRS, in particular when used in combination, have the capacity to provide useful data on parameters of high ecological relevance and thus have proven to be a highly valuable addition, if not alternative, to the classical methods. 
43

\section{Introduction}

Modern imaging modalities like Magnetic Resonance Imaging (MRI) and Computed Tomography (CT) are increasingly gaining attention in the field of zoology, in particular for morphological studies $[1,2,3]$. These non-invasive imaging techniques can easily picture the whole body of organisms in 3-dimensional (3D) digital data without the need for dissection. Supported by imaging graphic software tools, the data sets can be used to create anatomical and morphological 3D models discriminating between skeleton and organs or displaying the connectivity of, e.g., the entire cardiovascular system. Recently, MRI and CT have been successfully applied to create digital atlantes (e.g. of brains [4]) and libraries to document and store anatomical and morphological data of specimen from Natural Museums' collections, and to make these data available online for everyone (see www.digitalfishlibrary.org; [5]).

The main difference of MRI compared to other non-invasive imaging techniques is its excellent soft tissue contrast that allows detecting and illustrating structures, which are hard to unveil with classical dissection techniques [e.g. 6, 7]. The image contrast can be easily modified by running specific MRI sequences to produce a distinct discrimination between particular organs or other specific internal structures. In most tissues the contrast of MR images is primarily based on magnetic properties of water-bound hydrogen. However, in lipid-rich tissues lipid-bound hydrogen atoms significantly contributes to the image contrast, which can be utilized to image lipid-rich tissues and structures in specific body parts [e.g. 8].

The MRI, moreover, can be used in combination with Nuclear Magnetic Resonance Spectroscopy (NMR, MRS) to get localized and analytical information on, e.g., specific 
metabolites or lipid composition of organs and body structures. This approach has resulted in a multitude of applications of in vivo MRI and MRS in animals (for review see e.g. $[9,10])$.

However, alive animals for such studies are not always available. In these cases, preserved samples, either frozen or chemically preserved, may be studied instead. The most common chemicals used for sample preservation and long-term storage are ethanol and formalin. In particular formalin preservation has some clear advantages regarding tissue integrity of a sample or animal compared to freezing or the use of fresh tissues: fragile structures are not damaged by forming ice crystals and no water-loss occurs due to post-mortem celldegradation or warming. Chemically preserved samples are frequently available in the collections of museums, research institutes or universities. Often, these collections even include rare and/or highly valuable animals for which analyses of, e.g., tissue composition or internal structure using traditional destructive methods is not an option to be considered. For such samples or animals, non-invasive MRI and MRS represent perfect tools to study their internal structure without any damage.

Compared to the variety of in vivo applications, however, the applications of MRI to chemically preserved animals so far has been largely limited to general anatomical and morphological studies, such as the work done in the framework of the Digital Fish Library [5].

Here, we intent to move beyond the pure record and representation of general anatomy and morphology and to open these tools for ecological research. We extend the basic morphological approach and present a protocol containing standard MR imaging sequences in combination with MRS for studies on the structure and function of lipid-rich tissues (functional morphological MR) in preserved organisms. This protocol is simple to apply even for the non-expert MR user and demonstrated here using preserved samples of an Antarctic fish as an example. 
The Antarctic silverfish, Pleuragramma antarctica Boulenger, 1902 is one of the few truly pelagic fish species inhabiting high Antarctic waters and represents a major trophic link in the food web. As it is extremely difficult, if not almost impossible, to catch this fragile fish alive, studies usually have to rely on preserved samples. Structural analyses of this species are largely limited to histological studies of transverse tissue sections [e.g. 11,12,13]. Despite the lack of a swim bladder, Pleuragramma is almost neutrally buoyant; the lack of a swim bladder is mainly compensated by a reduced and low ossified bone mass (skeleton) and by large lipid deposits $[11,14,15,16]$. Fish have unconstricted vertebrae and a persistent notochord filling the hollow centra of adult vertebrae $[14,17]$. The lipids are mainly stored in intermuscular and subcutaneous lipid sacs $[11,14]$, which is a rather rare feature in fish. Whether the functional role of these lipids is exclusively limited to buoyancy, however, is still under debate [18].

In this study, we test for the capacity of MRI and MRS technologies to address and study ecologically relevant issues and features of fish species, such as Pleuragramma, when applied to preserved animals. As the lipid storage system in this fish species is very particular, we not only investigate the general anatomy and the potential to determine organ volumes, but also focus on the distribution and structure of the lipid sacs and the possibility to analyze the lipid composition. As investigating such measures of ecological interests using traditional methods (e.g., histological sections, chemical lipid extractions and analysis) is very time consuming and destructive, the modern tools used in this study might provide a useful addition or even alternative to draw a comprehensive ecological picture of a fish species. This non-invasive approach might prove particularly valuable for studying rare or highly valuable species. 


\section{Animal sampling}

Individuals of adult Pleuragramma were taken in the western Weddell Sea, east off the

Antarctic Peninsula (south of $60^{\circ} \mathrm{S}$ ) during the RV Polarstern expedition ANT XXVII-3 in 2011 [19]. Fish were caught between $64^{\circ} 47,00^{\prime} \mathrm{S} / 60^{\circ} 23,65^{\prime} \mathrm{W}$ and $65^{\circ} 31,68^{\prime} \mathrm{S} / 61^{\circ} 33,13^{\prime} \mathrm{W}$ by means of a standard bottom trawl and a bentho-pelagic net. The sampling of fish was conducted according to the ethics and guidelines of the German law, and approved by the

Federal Environment Agency (FEA; Umweltbundesamt, UBA, Wörlitzer Platz 1, 06844

Dessau-Roßlau), reference number I 3.5 - 94003-3/253, on February $1^{\text {st }} 2011$. Individuals were fixed in $10 \%$ formalin buffered with borax (sodium tetraborate) for preservation. To exemplify the capacities of MRI and MRS, individual animals were randomly chosen from the bulk of samples.

\section{MR imaging and spectroscopy}

Directly prior to MR scanning, individual fish were carefully removed from formalin to determine weight and standard length (SL, cm). Subsequently, the specimen was placed between two wooden skewers within a Perspex chamber to hold the fish in an upright position without damaging the skin. The Perspex chamber containing the fish was then positioned inside the magnet. All MRI and MRS studies were performed in a Bruker 4.7T magnet equipped with Avance III electronics. For high resolution MRI and MRS a $200 \mathrm{mT} / \mathrm{m}$ gradient coil insert (BGU 12) together with an $8 \mathrm{~cm}{ }^{1} \mathrm{H}$-birdcage resonator (Bruker Biospin, Germany) was used. Whole body analyses (e.g. total lipid content) were conducted using the 
136 (Bruker Biospin, Germany). Data acquisition and recording were carried out with ParaVision 5.1 (Bruker Biospin, Germany).

\section{Functional morphological MR}

Modified Driven Equilibrium Fourier Transform (MDEFT) imaging, as recommended for morphological MRIs [3], was used here to study the internal anatomy of preserved fish. Using a MDEFT sequence protocol from the ParaVision software, the general internal anatomy of a fish was investigated (2D) and its total body as well as stomach volume was determined (3D).

Prior to imaging, field homogeneity was optimized using an automated shim routine of the ParaVision software. The optimal morphological contrast was achieved using a fat suppression with a Gaussian pulse (700 Hz bandwidth). Parameters were as follows: Echo time TE $=7.59 \mathrm{~ms}$, Echo repetition time TER $=21.16 \mathrm{~ms}$, segments= 8, segment repetition time $=3353.75 \mathrm{~ms}$, segmentation duration $1354.24 \mathrm{~ms}$, number of averages: $64,90^{\circ}$ sinc10H pulse of 2 ms length, matrix size: 512x512, Field of view FOV $60 \times 60$ mm, 26 slices, slice thickness $0.5 \mathrm{~mm}$, maximum achievable resolution $0.117 \times 0.117 \mathrm{~mm} /$ pixel. The total acquisition time varied according to the number of averages from $5 \mathrm{~min}$ for an overview image for the positioning of the voxels used for localized ${ }^{1} \mathrm{H}-\mathrm{NMR}$ spectroscopy up to $12 \mathrm{~h} 24$ min for high-resolution images of the lipid sacs.

All images were post processed using MeVisLab (MeVis, Germany); to determine total body and organ volumes, the 3D data were processed with the modules 'region growing' and 'volume rendering'. The stomach was separated from the surrounding tissue with the 
equivalent to fish mass, which is together with body size the common measure in fish ecology, the relationship between individual body weight $w$ (conventionally measured) and body volume $v$ (measured in the MRI) was analyzed.

For MR imaging of lipid distribution different approaches were taken into account before starting the measurements. A search of the current literature on lipid quantification in fishes revealed that, e.g., the Dixon technique, which is one of the state of the art techniques for water-fat separation in medical research, yields unpersuasive results when applied to fishes [20]. The contrast enhancement effect of lipid in fast spin echo sequences [21] (e.g. the rapid acquisition with relaxation enhancement (RARE)) proved to be the most appropriate approach and was chosen for the analysis of preserved samples. A standard multi-slice RARE sequence protocol with the following parameters was used: TE= $14.9 \mathrm{~ms}$, RARE factor: 4, effective TEeff $=29.8 \mathrm{~ms}, \mathrm{TR}=5 \mathrm{~s}$, number of averages $30,90^{\circ}$ hermite pulse of $3 \mathrm{~ms}$ length, $180^{\circ}$ hermite pulse of $1.9 \mathrm{~ms}$, matrix $512 \times 256$, FOV $685 \times 86,4 \mathrm{~mm}, 14-18$ slices, slice thickness $1.12 \mathrm{~mm}$, total acquisition time $2 \mathrm{~h} 40 \mathrm{~min}$.

After interpolation of the multi slice data sets to 3D matrices (minimum size 64/512/64 depending on fish length) percent overall lipid content was calculated from volume rendered MRI scans using MeVis Lab in accordance with Machann and colleagues [22]. The lipid content of individual Pleuragramma was calculated by converting the number of pixels into a volume $v\left[\mathrm{~mm}^{3}\right]$. Bright pixels that arose from lipid-bound hydrogen atoms were separated from other tissues using an operator-controlled threshold of 165 pixel units. The remaining pixels were counted and summed up and finally divided from the overall sample volume. The lipid content of individuals is then expressed by the percentage of lipid volume of total fish body volume (i.e. lipid as \% of total body volume). 
The individuals of Pleuragramma that were used in this study are part of the institute's collections and are too rare and valuable to be destroyed for a direct validation of these results using chemical lipid extraction. Instead, previously published data on chemically determined lipid content (and composition) of Pleuragramma sampled also in the Weddell Sea were used to indirectly verify our measurements. For the comparison with these literature data, which are usually given in \% dry weight, a linear regression model based on Pleuragramma tissue wet weights and dry weights analyzed as part of Mintenbeck and colleagues [23] was used with a conversion factor of 0.154 to estimate initial dry weights of the specimens used in this study.

\section{${ }^{1} \mathrm{H}-\mathrm{NMR}$ spectroscopy and lipid composition}

Localized ${ }^{1} \mathrm{H}-\mathrm{NMR}$ spectroscopy was conducted for the analysis of lipid composition, i.e. fatty acid patterns in triacylglycerides $[24,25,26]$. Prior to spectroscopy, field homogeneity for the specific volume of interest (voxel) was optimized using FASTMAP [27]. A standard ${ }^{1} \mathrm{H}$ Point Resolved SpectroScopy (PRESS) sequence with the following parameters was used: $\mathrm{TE}=21 \mathrm{~ms}, \mathrm{TR}=5000 \mathrm{~ms}$, number of sampling points $2 \mathrm{k}, 256$ averages, acquisition time $21 \mathrm{~m}$ 40s. Individual voxels were placed inside specific regions of interest of the intermuscular lipid layers according to previous acquired multi-slice MRIs (see above). Size of individual voxel varied among samples and ranged from $3 \times 3 \times 3$ to $2 \times 2 \times 8 \mathrm{~mm}$, usually including $3-4$ lipid sacs within one voxel, resulting in a volume of interest between 27 and $32 \mathrm{~mm}^{3}$. Localised

${ }^{1} \mathrm{H}-\mathrm{MR}$ spectra from lipids within the lipid sacs were measured in preserved individuals sampled at two different locations in the Weddell Sea (Station A: area of the former Larsen A ice shelf; Station B: area of the former Larsen B shelf ice). Prior to the main analysis, we tested for within-fish and within-sampling location variability. There were no differences in 
lipid composition within lipid sacs from different positions within one individual fish.

208

209

210

211

212

213 Nevertheless, for the main analysis, the voxels for the localized MR spectroscopy in the lipid sacs were in each individual fish placed at the same position behind the first dorsal fin. The variability in lipid composition among individuals from one sampling location (Station A or B) was low.

Lipid composition was determined from the localized ${ }^{1} \mathrm{H}-\mathrm{MR}$ spectroscopy using the approach recently described by Machann et al. [22]. The signals in the ${ }^{1} \mathrm{H}-\mathrm{NMR}$ spectra were assigned to the respective triacylglyceride resonances according to Berglund et al. [26] and Petterson \& Månsson [28].

\section{Results and Discussion}

\section{General internal anatomy}

The Antarctic silverfish Pleuragramma antarctica possesses some very special anatomical features such as the lipid sacs, the less ossified skeleton and the persistent gelatinous notochord [14, 17]. Images of this species are not (yet) part of the Digital Fish Library [5] and it was uncertain whether morphological data could be pictured in sufficient quality from preserved samples of this species due to the high total lipid content and the heterogeneous lipid distribution; both might theoretically induce artifacts in MR images due to susceptibility changes resulting from local inhomogeneity between different tissues and chemical shift effects between lipid and water. To test the applicability of MRI to preserved tissues of the Antarctic silverfish for the first time and to gain a first overview of the general internal anatomy, high-resolution 2D and 3D MR imaging, as proposed by Ziegler et al. [3], were applied. 
Fig. 1 shows an example of a high-resolution morphological MR image of a multi-slice MR

231

232

233

set. The excellent soft tissue contrast of the MR imaging technique allowed a clear distinction of muscle (M), notochord (N) and different organs such as brain (B), liver (Lv), and stomach (S) in the sagittal morphological section (Fig. 1A). There was no sign of any B0 or B1 inhomogeneity, indicating a very homogeneous excitation profile. Between outer skin and muscles, series of lipid sacs (ILS) can be identified in the dorsal part of the body along the back and in the ventral part of the body behind the abdomen (Fig. 1A). Fig. 1B shows a transversal MRI section taken from a 3D-morphological data set of a sample from this study in comparison to a histological cross (transversal) section of Pleuragramma from Eastman \& DeVries [14] shown in Fig. 1C. Both transversal sections (Fig. 1B \& C) are from the posterior one-fifth of the body of an adult individual [cf. 14, 17]. In the MRI slice muscle tissue is reflected in grey, whereas the lipids (ILS, SLS, IAT; Fig. 1B) generate a dark to almost no contrast. The details on the MR image are in well agreement with the histological image; even the thin collar of vertebral bone surrounding the notochord is visible. Besides of the large muscles, also the dorsal (DFM) and anal fin muscles (AFM) as shown in Johnston et al. [13] in histological sections (not shown here) can be identified on the MR image. Due to the lower resolution of MR images compared to histological images, very small details such as single muscle fibers or vacuoles and myocellular lipids $[14,17]$ can't be identified. However, despite of the lower resolution, the morphological imaging data sets obtained from nondestructive MRI technique provide almost the same array of information without the necessity to dissect and destroy the animal. In addition, despite of the high lipid content and heterogeneous structure, the MR images of preserved samples of Pleuragramma are of the same quality as, e.g., images from other (Antarctic) fish species such as Notothenia corriiceps as shown in the Digital Fish Library (see www.digitalfishlibrary.org). 
As the lipid sacs in Pleuragramma are a rare feature among fish, their structure was studied

255

256

257

258

259

260

261

in more detail. Within one particular fish and among individuals from the same sampling area, the shape of the single lipid sacs was similar. This was not the case among individuals from different areas. In Fig. 2 the high-resolution MRI scans of two individuals from different sampling regions are shown. The yellow boxes in both examples display almost identical positions within the fish. In the scan on the left, the lipid sacs are well separated from each other, while in the scan on the right the sacs are much more densely packed and display a much brighter image contrast (in particular within the yellow box). The reason for these differences still needs to be clarified. However, such morphological features of fragile objects like the lipid sacs get lost when using destructive techniques, but can be perfectly identified and analyzed in chemically preserved samples with non-invasive digital imaging approaches such as MRI.

\section{Organ volume}

Beside the representation of anatomic structures and details, the morphological MRI can produce 3D MR imaging data sets, e.g. from the abdominal region, which can be used to determine the volume of the specimen and specific organs of interest, such as the stomach (Fig. 3). The gastric wall exhibited a bright contrast in this MDEFT image set (see Fig. 3A-C), which could be easily separated from the other tissues using volume rendering tools (see Material \& Methods). The rendered volume of one stomach is exemplarily shown in Fig. 3D. To show that the volume data measured in the MRI are comparable with conventional, ecological data, which are usually in units of weight (or size), the relationship between individual body weight (conventionally measured) and body volume (measured in the MRI) is shown in Fig. 4. According to these data, the relationship between both measures is almost 
1:1 $\left(y=0.998 x, R^{2}=0.979\right)$, validating the comparability of body volume and body weight (i.e. $1 \mathrm{ml} \approx 1 \mathrm{~g}$ ). Given that body volume $v$ is a function of body weight $w$ and body density $\rho$ $(v=w / \rho)$, the slope close to 1 is not surprising: Pleuragramma is almost neutrally buoyant, hence, its body density should be close to the density of the seawater, which on the high Antarctic shelf is about $1.03 \mathrm{~g} \mathrm{~cm}^{-3}$ ( $35 \mathrm{psu},-1,8^{\circ} \mathrm{C}$ ). Accordingly, a body density $\rho$ close to $1 \mathrm{~g}$ $\mathrm{cm}^{-3}$ can be expected for Pleuragramma, which means that for this species $v \approx w$.

The volume of a stomach and the thickness of the gastric wall vary strongly depending on stomach fullness. Both, volume and wall thickness, are thus valuable indicators for the nutritional state of a fish and may be particularly useful for temporal or spatial comparisons of individuals in studies on a species' feeding habits. At present, in fish ecology, stomach fullness is determined gravimetrically or using rather subjective indices [29], both requiring dissection of the animals of interest and a lot of time.

Another important but time-consuming measure in fish ecology, beside stomach fullness, is the analysis of stomach content composition. Here, the limited gradient power (maximum of $200 \mathrm{mT} / \mathrm{m}$ ) of the MR imaging system used in this study did not allow (with some exceptions) for identifying details of the stomach content. However, current animal scanners equipped with more powerful gradient systems of field strengths above $1000 \mathrm{mT} / \mathrm{m}$ can easily reach an in plane resolution below $100 \mu \mathrm{m}$. Using such systems, the identification of particular prey organisms should be feasible (unless they are too heavily digested). exemplified using stomachs of fish. The same methodology can be also applied to, e.g., the liver. In fish, the liver serves as an energy storage and is therefore smaller (and less heavy) in poor environments. Accordingly, in fish ecology, the ratio of liver to body weight (Hepatosomatic Index, HSI) is used as a measure of fish condition [30]. Intraspecific 
comparison of liver volume using morphological MRI can therefore provide valuable information on conditions and prey availability in the area/season of capture.

\section{Lipid content}

Besides the excellent soft tissue contrast for morphological or anatomical observations, MR techniques can clearly separate tissue water from lipid and are frequently used for fat-water separation in medical research [for a review see 30]. Accordingly, MR techniques are frequently used for the analysis of body-fat content in vivo [10]. Recently, such MR analyses were also applied to fresh and defrosted fish tissue for an assessment of, e.g., food quality $[20,31,32]$. However, to our knowledge, these techniques to analyse body lipid content have never been applied to chemically preserved samples, before. As lipids in fish play an important role as energy reserve and in some species, such as Pleuragramma, also contribute to buoyancy, the proportion of lipids in the body is a measure of high interest in fish ecology. This particularly applies in the case of adult Pleuragramma, where the functional role of lipids is still under debate [18].

In species using lipids primarily as energy reserve, total body lipid content is significantly positively correlated to fish condition [33]. In Pleuragramma overall lipid content was shown to vary with fish body size and life cycle [34, 35, 36, 37]; in Pleuragramma larvae total lipid content was used as a marker for the nutritional condition [38].

In Fig. 5B, the blue areas show the lipid fractions depicted with volume rendering and contrast thresholds (see Material \& Methods) from the RARE imaging data. The distribution of lipids obtained from the RARE images is in very well agreement with the distribution in the histological sections from Eastman [15, 17] and Eastman \& DeVries [14]. Even the thin 
lipid layer surrounding the vertebral thin collar and the notochord can be identified on the MR image (Fig. 5B). The notochord itself does not contain lipids (as shown by the lack of blue color). This is a clear improvement to the morphological data acquired with the MDEFT sequence, where the notochord and lipids were not clearly distinguishable (see Fig. 1B).

The total lipid content of Pleuragramma, as determined from the RARE scans, averaged 9.9 $\pm 1.7 \%$ of wet weight (WW) and $51 \pm 9 \%$ of dry weight (DW; converted), respectively ( $n=5$; mean individual body weight: $15 \pm 1 \mathrm{~g} \mathrm{WW}$; mean standard length, SL: $13.7 \pm 0.2 \mathrm{~cm}$ ). These results are in very good agreement with literature data on lipid content analyses based on chemical extraction from similar-sized Pleuragramma from the Weddell Sea (mean SL: 15.5 $\mathrm{cm}$, mean lipid contents: $10.2 \% \mathrm{WW}$ and $47 \% \mathrm{DW}$; see [34]) and demonstrate the suitability of RARE imaging for lipid determination in preserved fish samples.

\section{Lipid composition}

Triacylglycerides and wax esters are the most common lipid classes in marine organisms including fish. Both lipid classes are used as energy reserve and buoyancy aid. Lipid composition of fish is influenced by the diet, because the fatty acid profile of a consumer reflects the fatty acids of its prey and its nutrition value $[39,40,41]$. Accordingly, lipid class composition and fatty acid signatures are commonly used markers to analyze consumers' trophic ecology $[42,43,44]$. Recently, it has been shown that the lipid composition of adipose tissue and lipid stores can be determined in humans and mammals using localized

${ }^{1} \mathrm{H}-\mathrm{NMR}$ spectroscopy (see Material \& Methods). The ratios of the ${ }^{1} \mathrm{H}-\mathrm{NMR}$ signals of the fatty acids can be used for the calculation of mean chain length, unsaturation status and the mono- and poly-unsaturation fractions of triacylglycerides, as shown for instance by 
Berglund et al. [26]. Here, localized ${ }^{1} \mathrm{H}-\mathrm{NMR}$ spectroscopy was applied to analyze the composition of lipids stored in the intermuscular sacs (ILS) of Pleuragramma.

Figure 6 presents the localized ${ }^{1} \mathrm{H}-\mathrm{NMR}$ spectra from two individuals sampled at two different locations in the Weddell Sea (Station A and Station B, see Material and Methods for details). The measured spectra show a typical lipid pattern and the particular signals could be assigned to hydrogen atoms bound in specific positions of fatty acids according to the literature $[22,24,2454]$. The signal intensities reflect the relative concentration of hydrogen atoms bound to specific lipid groups and the signal of the $\mathrm{CH}_{3}$-group can be used as an internal standard for calibration [22]. According to the spectra in Fig. 6 the dominating lipid class in the lipid sacs of Pleuragramma is triacylglyceride, which is in accordance with results on muscle tissue and overall lipid content determined using classical chemical lipid analyses $[11,45,46]$. Interestingly, distinct differences are also obvious between both spectra: e.g. the signals from the $-\left(\mathrm{CH}_{2}\right)$ - and the $-\mathrm{CH}_{2}-\mathrm{CH}=\mathrm{CH}-\mathrm{CH}_{2}$ - group are much more pronounced in the individual from Station A in Fig. 6. These differences are confirmed by the detailed results from the ${ }^{1} \mathrm{H}-\mathrm{NMR}$ spectra summarized in Table 1 . While the average chain length was similar in individuals from both sampling stations ( $\&$ \&), the lipids of individuals from the two locations significantly differed in their unsaturated and polyunsaturated degree $(p<0.05)$. Though the actual causes for these differences remain unsolved, so far, such differences might indicate potential functional changes within the lipid sacs induced by specific changes in energy/lipid metabolism of the organism.

Because of the fragile nature of the lipid sacs, an analysis of localized lipid composition inside the structures seems almost impossible using traditional, destructive methods. Here,

370 the composition inside this particular lipid storage system was analysed for the first time using ${ }^{1} \mathrm{H}-\mathrm{NMR}$ spectroscopy. 


\section{To be considered when working with preserved samples}

All kinds of sample preservation affect tissues of organisms in one or the other way. Potential effects differ among preservation method and may involve, e.g., alterations in biochemical composition, shrinkage due to water extraction or cell disruption. Formalin and its derivates may induce changes in size and weight, as shown for instance in mice brain [46]. Formalin fixation thus may result in an underestimation of measured organ volume of a preserved sample, though the reported changes are only in the range of a few percentages. Formalin (as well as methanol) may cause hydrolysis of tissue lipids and degradation of polyunsaturated fatty acids and phospholipids [48, 49], while neutral lipids are obviously not affected [50]. Most changes apparently occur during a short time frame directly after exposure to the preservation medium, within the first few hours or days; during this period, measurements and analyses of preserved samples should be avoided [51]. In some studies no significant effect of formalin on biochemical composition of tissue and samples, respectively, was found $[52,53]$; other studies considered a potential effect negligible, at least as long as the lipid containing tissues are intact $[54,55]$.

In the present study, whole, undamaged animals were used, without any defects in the skin that might have facilitated leakage of lipids from the lipid sacs. The MRI studies were started about one year after fixation in $10 \%$ buffered formalin and repeated in part after another year of formalin storage. No significant difference in weight, volume or shape could be detected between the two time points, nor was there a difference in measured total lipid content (personal observation). The risk of lipid loss is expected to be increased in tissues samples (e.g. liver) that are directly exposed to the preservative. Whole organisms, with intact intestines and tissues, are most likely less affected. However, some formalin-induced 
short term release of e.g. phospholipids can't be completely excluded. As lipids in

397

398

399

400

401

402

403

404

405

406

407

408

409

410

411

412

413

414

415

416

Pleuragramma are mainly represented by neutral triacylglycerides (in particular inside the lipid sacs) while the amount of phospholipids is very low [37, 46], a potential effect of the preservation on overall lipid content and composition is considered negligible, here; in particular because treatment, preservation and storage were identical for all individuals. Nevertheless, for future MRI studies such potential effects of the preservation methods needs to be taken into account, particularly when different preservation methods are used or preserved samples are compared to fresh material.

\section{Conclusions}

As shown in this study, MRI and MRS on preserved fish samples may not only contribute anatomical and morphometric 3D data to digital libraries and atlantes, but also provide valuable insights into functional morphology (organ volumes, lipid distribution), energetics (lipid content) and biochemical composition (lipid composition). Using MRI, lipid content and organ volumes can be reliably determined. Unexpected and unknown differences in the shape of lipid sacs among individuals, that would have been hardly found using traditional methods, could be detected. ${ }^{1} \mathrm{H}-\mathrm{NMR}$ spectroscopy proved to be a valuable tool to analyze lipid composition, which usually requires destruction of the animal and complex chemical lipid exaction and analysis. The localized spectroscopy allowed for the first analysis of lipid composition inside the lipid sacs and revealed differences in lipid composition among individuals from different sampling stations.

Lipid distribution, content and composition as well as organ volumes are all parameters of high ecological relevance. For the study of preserved samples, MRI and MRS proved to be a 
highly valuable addition, if not alternative, to the classical methods. The advantage that these modern techniques are non-invasive and non-destructive opens an array of opportunities for studies of preserved samples from natural history museums' collections.

422

\section{Acknowledgements}

424 We like to thank Prof. Dr. Rascher-Friesenhausen for providing a MeVis Lab software licence 425 and the crew and officers of FS Polarstern during ANTXXVII/3 for their professional support. 426 We also acknowledge the American Society of Ichthyologists and Herpetologists (ASIH), in 427 particular the Editor of Copeia, Christopher Beachy, for granting permission to reprint Fig. 2A 428 from Eastman \& DeVries [14] (Fig. 1C in this manuscript). Two anonymous reviewers 429 provided helpful comments on an earlier version of the manuscript. This work including 430 animal sampling and analyses were funded by the German Research Foundation (DFG, SSP 431 1158), grant MI 1391/1-1.

432

433

434

435

436

437

438 
[1] Baker M. (2010) The whole picture. Nature. 463: 977-980.

[2] Lauridsen $\mathrm{H}$, Hansen $\mathrm{K}$, Wang $\mathrm{T}$, Agger $\mathrm{P}$, Andersen JL, Knudsen PS, Rasmussen AS, Uhrenholt L, Pedersen M (2012) Inside out: modern imaging techniques to reveal animal anatomy. PloS One 6: e17879.

[3] Ziegler A, Kunth M, Mueller S, Bock C, Pohmann R, Schröder L, Faber C, Giribet G (2011) Application of magnetic resonance imaging in zoology. Zoomorphology 130: $227-254$.

[4] Simões JM, Teles MC, Oliveira RF, Van den Linden A, Verhoye M (2012) A

[5] Berquist RM, Gledhill KM, Peterson MW, Doan AH, Baxter GT, Yopak KE, Kang 
[9] Van der Linden A, Verhoye M, Pörtner HO, Bock C (2004) The strengths of invivo Magnetic Resonance Imaging (MRI) to study environmental adaptational physiology in fish. MAGMA 17: 236-248.

[10] Chatham JC, Blackband SJ (2008) Nuclear magnetic resonance spectroscopy and imaging in animal research. ILAR J 42: 189-208.

[11] DeVries AL, Eastman JT (1978) Lipid sacs as a buoyancy adaptation in an Antarctic fish. Nature 271: 352-353.

[12] Eastman JT (1988a) Ocular morphology in antarctic notothenioid fishes. J Morphol 196:283-306.

[13] Johnston IA, Camm J-P, White M (1988) Specialisations of swimming muscles in the pelagic Antarctic fish Pleuragramma antarcticum. Mar Biol 100: 3-12.

[14] Eastman JT, DeVries AL (1982) Buoyancy studies of notothenioid fishes in McMurdo Sound, Antarctica. Copeia 2: 385-393.

[15] Eastman JT (1985) The evolution of neutrally buoyant notothenioid fishes: Their specialization and potential interactions in the Antarctic marine food web. In: Siegfried WR, Condy PR, Laws RM, editors. Antarctic Nutrient Cycles and Food Webs. Springer Berlin Heidelberg. Pp. 430-436.

[16] Eastman JT (1997) Phyletic divergence and specialization for pelagic life in the Antarctic nototheniid fish Pleuragramma antarcticum. Comp Biochem Physiol 118A: 1095-1101.

[17] Eastman JT (1988b) Lipid storage systems and the biology of two neutrally buoyant Antarctic Notothenioid fishes. Comp Biochem Physiol 90B: 529-537.

[18] Maes J, Van de Putte A, Hecq JH, Volckaert FAM (2006) State-dependent energy allocation in the pelagic Antarctic silverfish Pleuragramma antarcticum: 
trade-off between winter reserves and buoyancy. Mar Ecol Prog Ser 326: 269-282.

488

489

490

491

492

493

494

495

496

497

498

499

500

501

502

503

504

505

506

507

508

509

510

[19] Knust R, Gerdes D, Mintenbeck K, editors (2012) The Expedition ANTARKTIS XXVII/3 CAMBIO) of RV "Polarstern" in 2011. Rep Polar Mar Res 644. 200pp.

[20] Brix O, Apablaza P, Baker A, Taxt T, Grüner R (2009). Chemical shift based MR imaging and gas chromatography for quantification and localization of fat in Atlantic mackerel. J Exp Mar Biol Ecol 2009;376(2):68-75.

[21] Henkelman RM, Hardy PA, Bishop JE, Poon CS, Plewes DB (1992). Why fat is bright in RARE and fast Spin-Echo imaging. J Magn Reson Imag 2: 533-540.

[22] Machann J, Stefan N, Schabel C, Schleicher E, Fritsche A, Würslin C, Häring HU, Claussen CD, Schick F (2012) Fraction of unsaturated fatty acids in visceral adipose tissue (VAT) is lower in subjects with high total VAT volume - a combined $1 \mathrm{H}$ MRS and volumetric MRI study in male subjects. NMR Biomed 26: 232-236.

[23] Mintenbeck K, Brey T, Jacob U, Knust R, Struck U (2008) How to account for the lipid effect on carbon stable-isotope ratio /d13C): sample treatment effects and model bias. J Fish Biol 72: 815-830.

[24] Ye Q, Danzer CF, Fuchs A, Vats D, Wolfrum C, Rudin M (2012) Longitudinal evaluation of hepatic lipid deposition and composition in ob/ob and ob/+ control mice. NMR Biomed 29: 1079-1088.

[25] Lee Y, Jee H-J, Noh H, Kang G-H, Park J, Cho J, Cho J-H, Ahn S, Lee C, Kim O-H, Oh B-C, Kim H (2013) In vivo 1H-MRS hepatic lipid profiling in nonalcoholic fatty liver disease: An animal study at 9.4 T. Magn Reson Med 70: 620-629.

[26] Berglund J, Ahlström H, Kullberg J (2012) Model-based mapping of fat unsaturation and chain length by Chemical Shift Imaging - phantom validation and in vivo feasibility. Magn Reson Med 68: 1815-1827. 
[27] Gruetter R (1993). Automatic, localized in vivo adjustment of all first and second-order shim coils. Magn Reson Med 29:804-811.

[28] Petterson P, Månsson S (2013) Simultaneous quantification of fat content and fatty acid composition using MR imaging. Magn Reson Med 69: 688-697.

[29] Dalpado P, Gjøsæter J (1988) Feeding ecology of the laternfish Benthosema pterotum from the Indian Ocean. Mar Biol 99: 555-567.

[30] Lloret J, Gil de Sola L, Souplet A, Galzin R (2002) Effects of large-scale habitat variability on condition of demersal exploited fish in the north-western Mediterranean. ICES J Mar Sci 59: 1215-1227.

[31] Toussaint C, Fauconneau B, Médale F, Collewet G, Akoka S, Haffray P, Davenel trout (Salmo trutta) by MR imaging. Aquaculture 243: 255-267.

[32] Picaud J, Collewet $G, *$, Idier J. (2016). Quantification of mass fat fraction in

[33] Herbinger CM, Friars GW (1991) Correlation between condition factor and 527-529.

[34] Friedrich C., Hagen W. (1994). Lipid contents of five species of notothenioid fish from High-Antarctic waters and ecological implications. Polar Biol 14: 359-369. composition of the Antarctic fish Pleuragramma antarcticum. Influence of age class. 
[37] Reinhardt SB, van Vleet ES (1985) Lipid composition of Antarctic midwater fish. Ant J US 19:144-145.

[38] Giraldo C, Mayzaud P, Tavernier E, Irisson J-O, Penot F, Becciu J, Chartier A, Boutoute M, Koubbi P (2013) Lipid components as a measure of nutritional condition in fish larvae (Pleuragramma antarcticum) in East Antarctica. Mar Biol 160: 877-887. and fatty acid composition in muscle and liver of two notothenioid fishes from Admiralty Bay (Antarctica): an eco-physiological perspective. Polar Biol 24:735-743.

[40] Lea M-A, Nichols PD, Wilson G (2002) Fatty acid composition of lipid-rich myctophids and mackerel icefish (Champsocephalus gunnari) - Southern Ocean food-web implications. Polar Biol 25: 843-845. triacylglycerols in myctophid fishes from the Southern Ocean. Antarct Sci 11: 436444.

Iverson S J, Field C, Bowen WD, Blanchard W (2004) Quantitative fatty acid signature analysis: A new method of estimating predator diets. Ecol Monogr 74: 211235.

[43] Nyssen F, Brey T, Dauby P, Graeve M (2005) Enhanced analysis of trophic

[44] Alfaro AC, Thomas F, Sergent L, Duxbury M (2006) Identification of trophic interactions within an estuarine food web (northern New Zealand) using fatty acid biomarkers and stable isotopes. Estuar Coast Shelf Sci 70: 271-286. 
[45] Hubold G, Hagen W (1997) Seasonality of feeding and lipid content of Pleuragramma antarcticum (Nototheniidae) in the southern Weddell Sea. In: Battaglia B, Valencia J, Walton DWH, editors. Antarctic communities: species, structure and survival. Cambridge University Press, Cambridge. Pp. 277-283.

[46] Hagen W, Kattner G, Friedrich C (2000) The lipid compositions of highAntarctic notothenioid fish species with different life strategies. Polar Biol 23: 785791.

[47] Weisbecker $V$ (2012) Distortion in formalin-fixed brains: using geometric morphometrics to quantify the worst-case scenario in mice. Brain Struct Funct 217: 677-685.

[48] Morris RJ (1972) The preservation of some oceanic animals for lipid analysis. J Fish Res Board Can 29: 1303-1307. 129: 65-69.

[50] Kapiris K, Miliou H, Moraitou-Apostolopoulou M (1997) Effects of formaldehyde preservation on biometrical characters, biomass and biochemical composition of Acartia clause (Copepoda, Calanoida). Helgolander Meeresun 51: $95-$ 106.

[51] Steedman HF, editor (1976) Zooplankton fixation and preservation. The Unesco Press, Paris. 350p. (1999) Seasonal variation in the biochemical composition of deep-sea nematodes: bioenergetic and methodological considerations. Mar Ecol Prog Ser 179: 273-283. 
preservatives on the composition of organic matter in a sediment trap experiment. J

584

585

586

587

588

589

590

591

592

593

594 Mar Res 51: 669-696.

[54] Davies KTA, Ryan A, Taggart CT (2012) Measured and inferred gross energy content in diapausing Calanus spp. in a Scotia shelf basin. J Plankton Res 34: 614625.

[55] Heulett ST, Weeks SC, Meffe GK (1995) Lipid dynamics and growth relative to resource level in juvenile Eastern Mosquitofish (Gambusia holbrooki: Poeciliidae). Copeia 1: 97-104. 
Figure 1: Example of a high-resolution morphological MRI scan obtained from a formalin preserved sample of Pleuragramma using MDEFT. The figure shows a sagittal section (A) and a transversal (cross) section (B) of an individual analyzed in this study in comparison to (C) a histological transversal section of Pleuragramma from Eastman \& DeVries [14] (with kind permission from Copeia and the American Society of Ichthyologists and

600

601

602

603

604

605

606

607

608

609

610

611

612

613

614

615

616

617

618

619

620

621

622

623

624

625

Figure 2: Magnification of high-resolution MRI scans (MDEFT) of the dorsal lipid sac region from two different Pleuragramma individuals sampled at different areas. Note the different shape of the lipid sacs between both examples (see yellow boxes).

Figure 3: Examples of 3D MR image sets (MDEFT) taken in the abdominal region of preserved Pleuragramma. Shown are a sagittal (A), a coronal (B) and a transversal section (C). On the right, the 3D surface-rendered stomach (D), as used for volume determination, is shown.

Figure 4: Relationship between individual body weight $[\mathrm{g}]$ and body volume [ml] in Pleuragramma $(\mathrm{N}=6)$. Dashed line represents the linear relationship described by $y=0.997 x\left(R^{2}=0.98\right)$. Note the excellent correlation that allows a direct conversion from volume into weight.

Figure 5: Example of a whole body 3D MRI data set acquired with RARE of Pleuragramma used for the analysis of body lipid content. In (A) a sagittal, a coronal and a transversal section are shown; lipids are bright/white, other tissues are grey. In (B) an example of a transversal MRI after volume rendering is shown, illustrating the muscle/water (grey) and lipid (blue) distribution in Pleuragramma.

Figure 6: ${ }^{1} \mathrm{H}-\mathrm{NMR}$ spectra measured in the dorsal intermuscular lipid sacs (ILS) of two different individual fish from two sampling locations (Stations A and B). The ROI (volume from where the spectrum was acquired) are marked by the red square. Both NMR spectra display a "typical" triacylglyceride/lipid pattern, but show clear differences in specific signal intensities. 


\section{A}

E

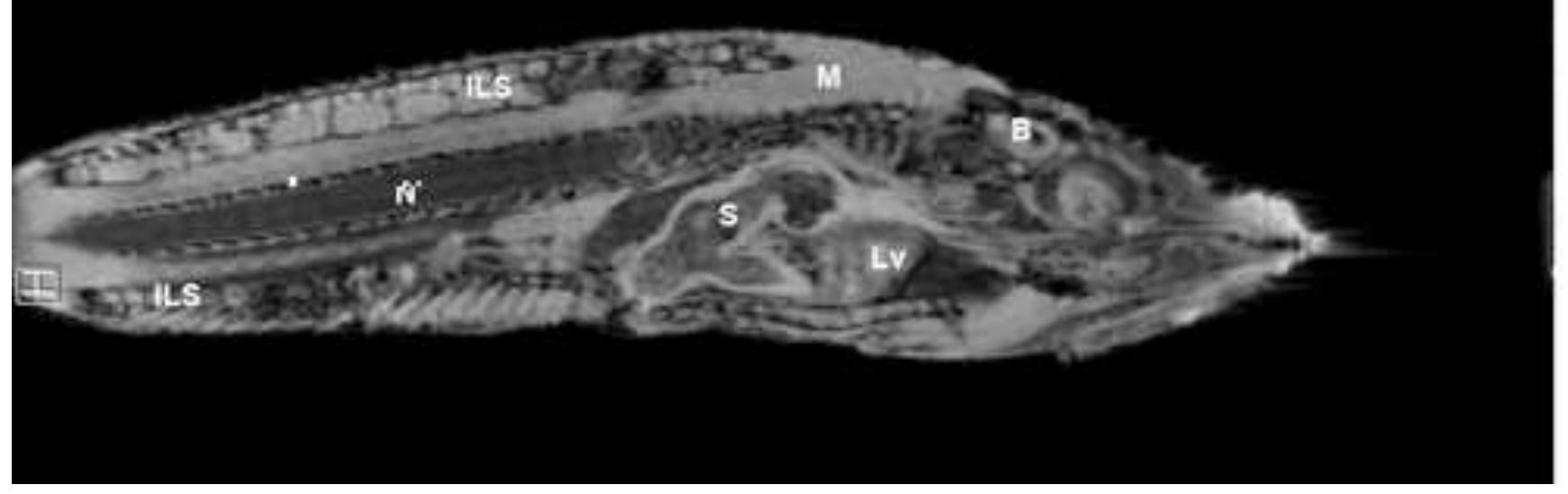

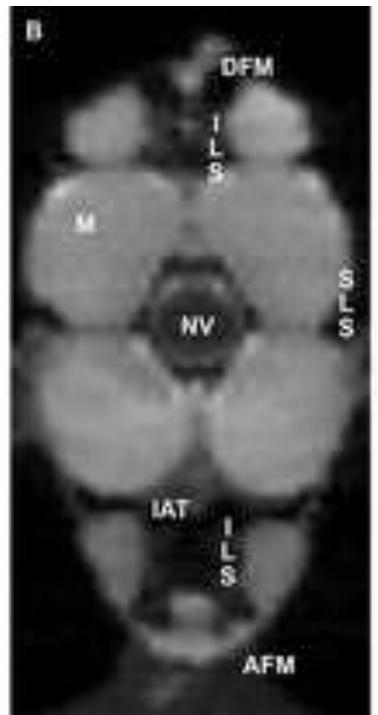

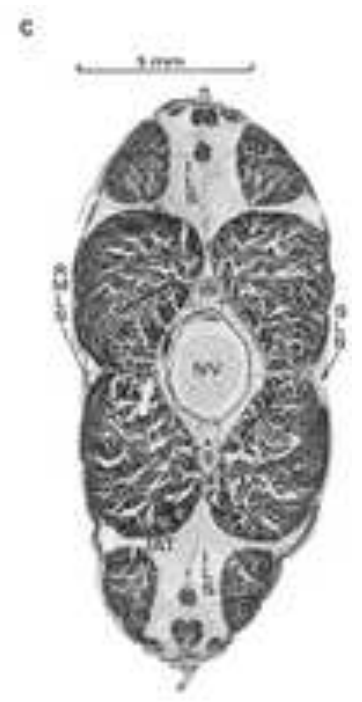


Click here to download high resolution image

A

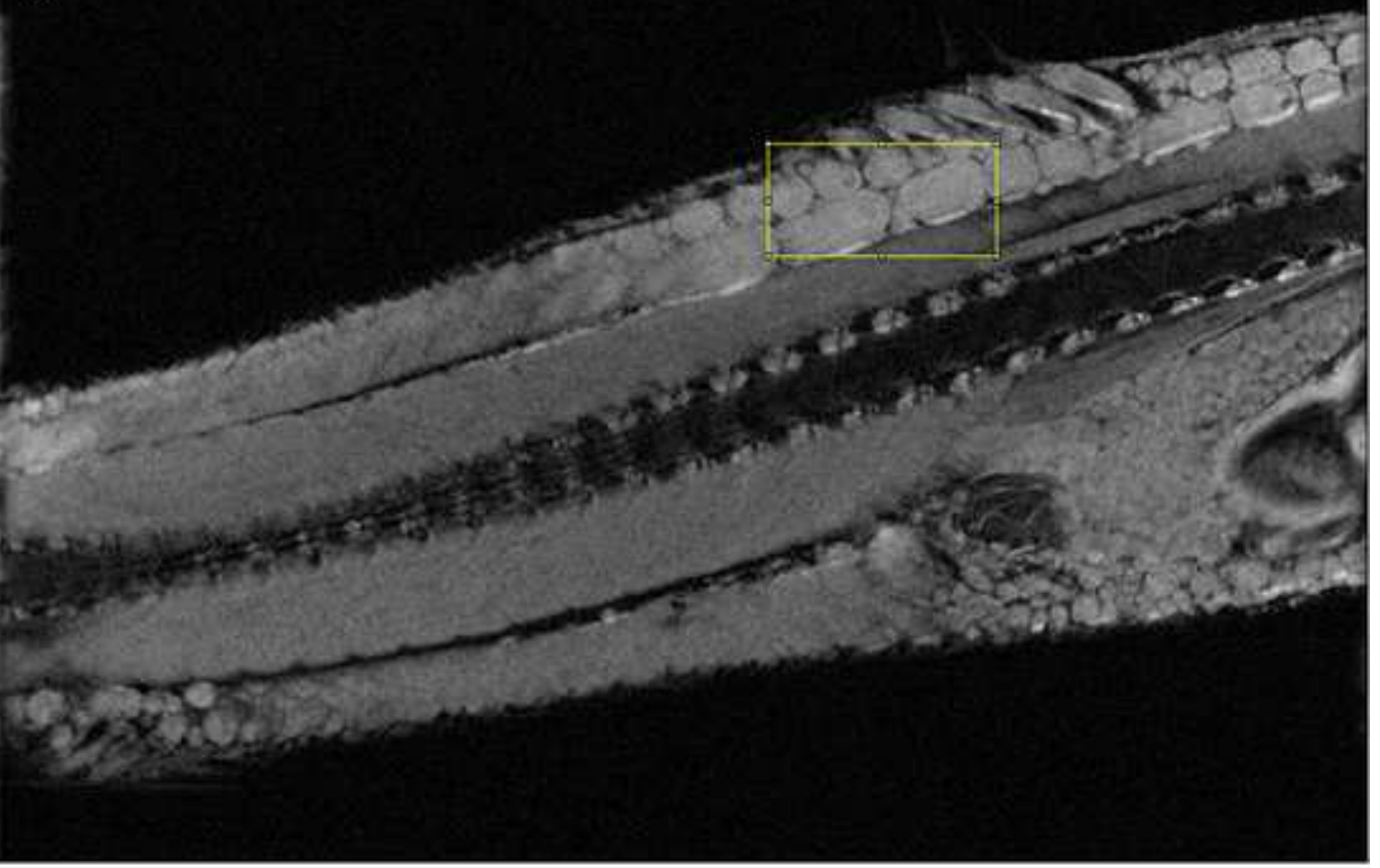

B

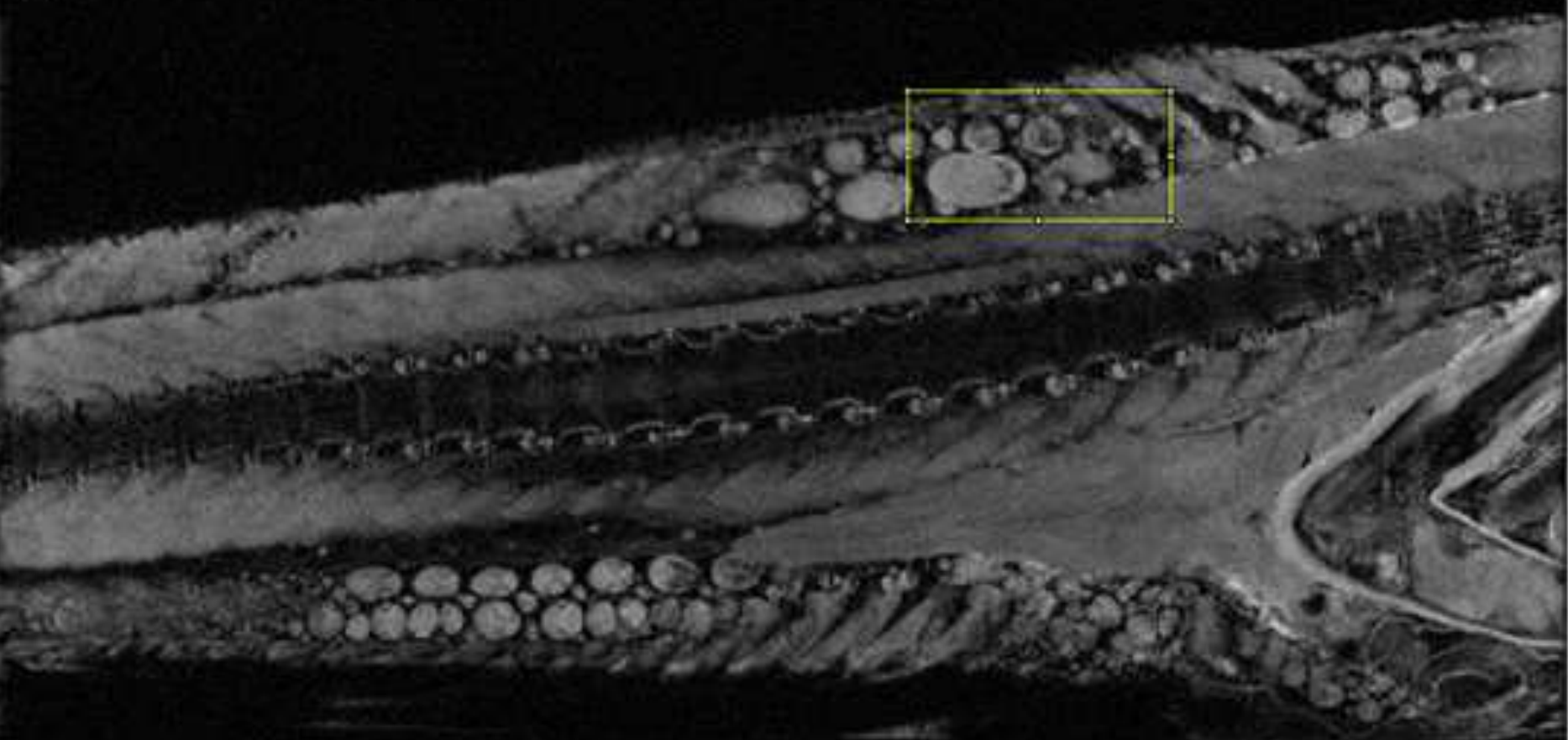


Click here to download high resolution image
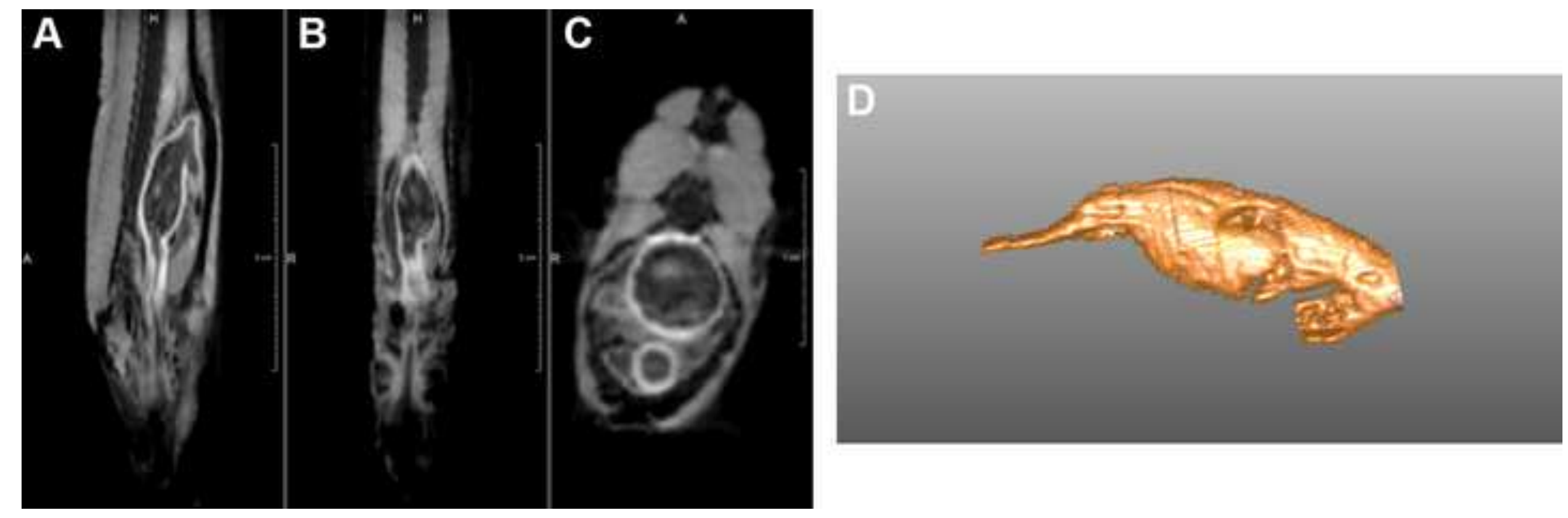


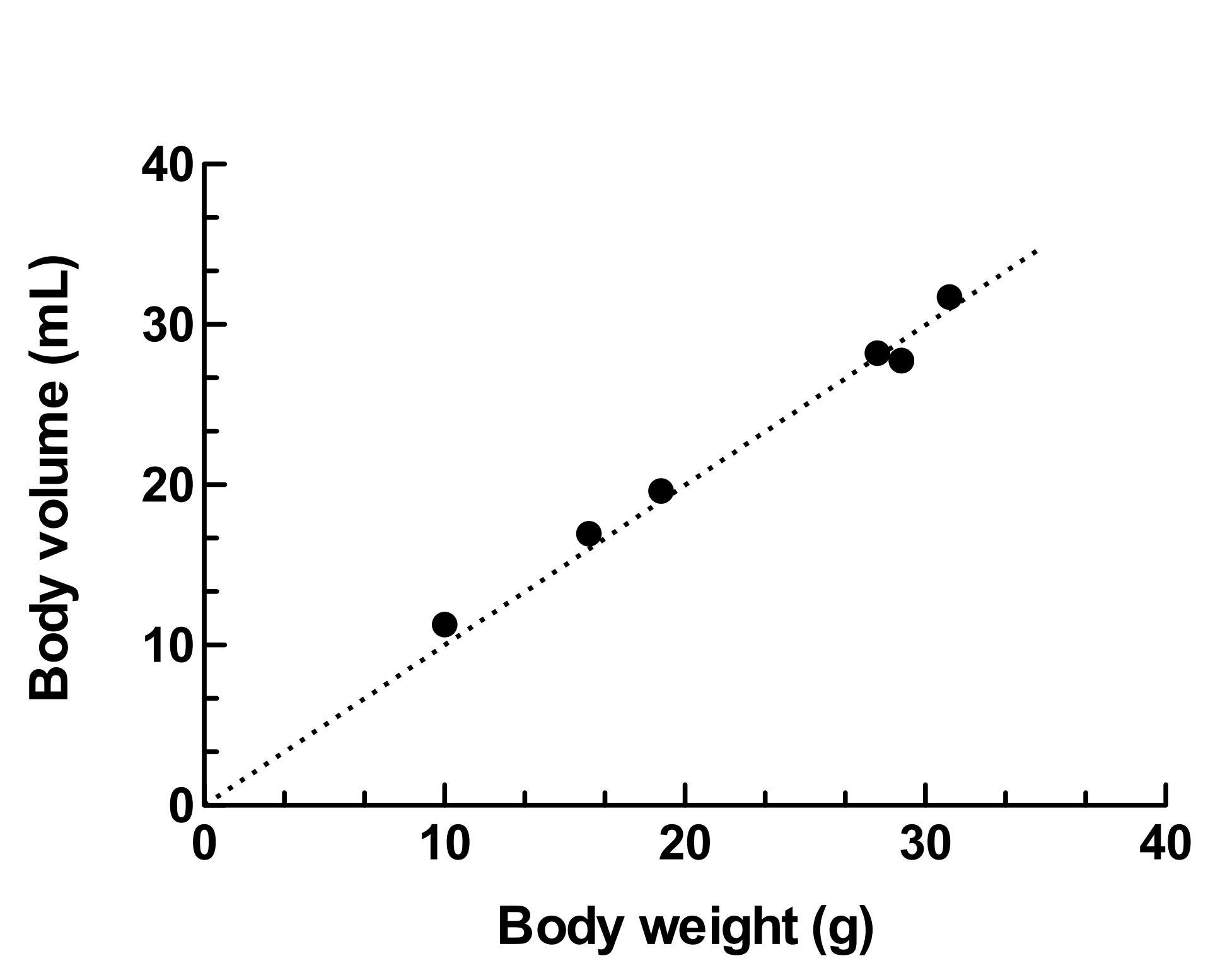

Figure 4

Figure 4 


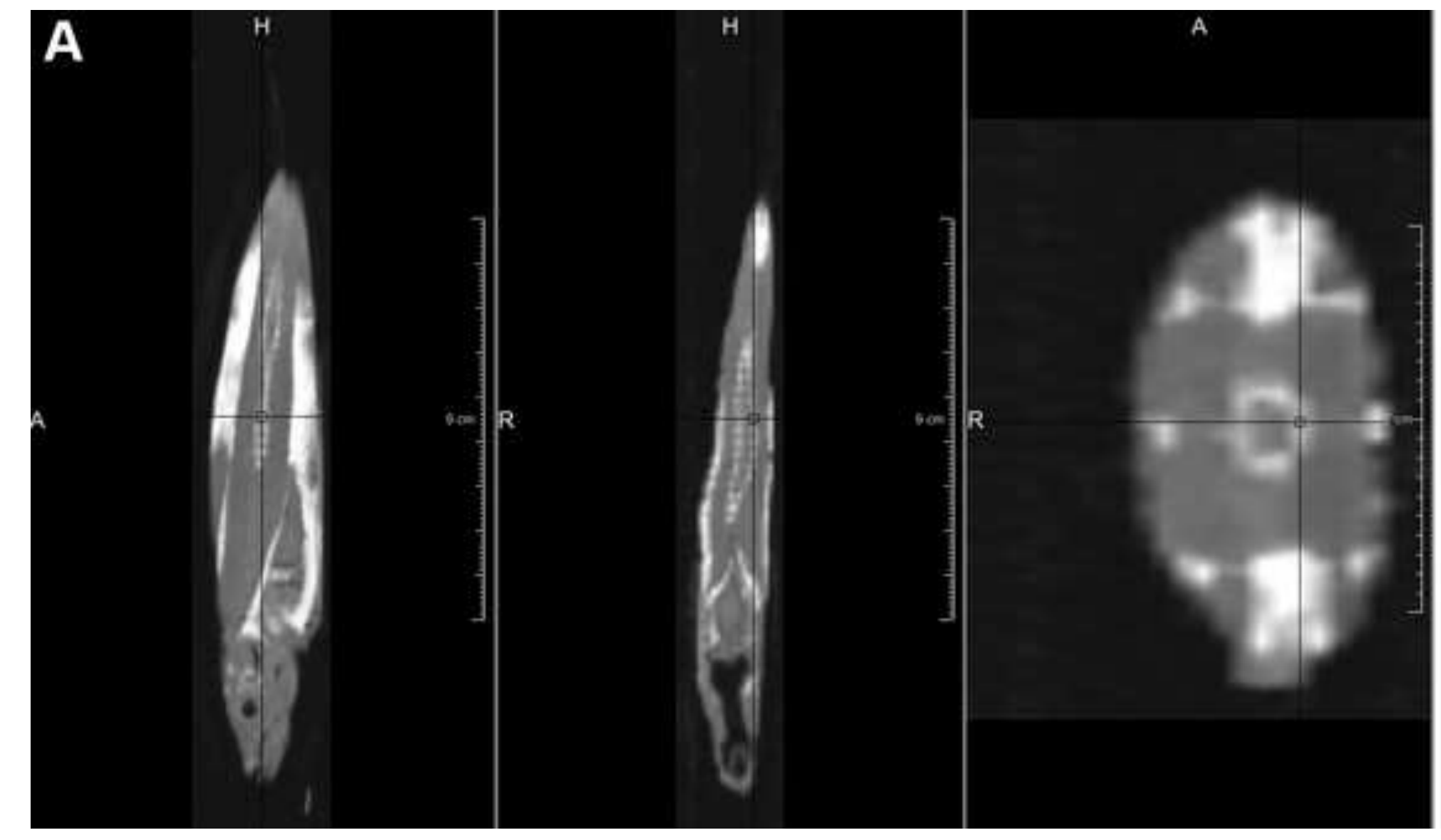

B

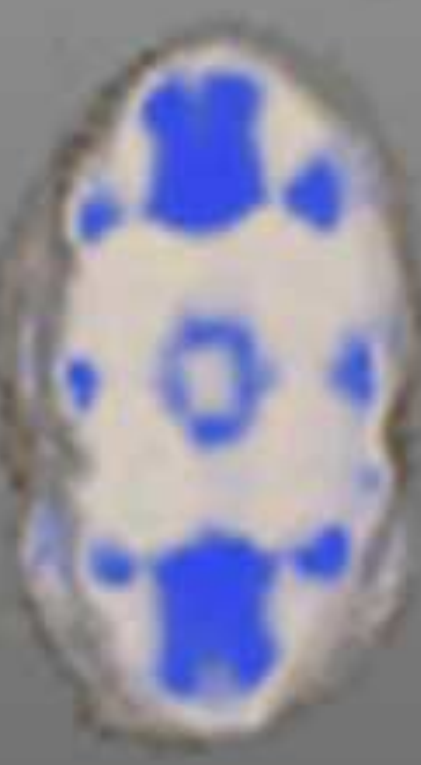

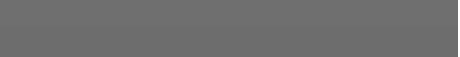


Click here to download high resolution image

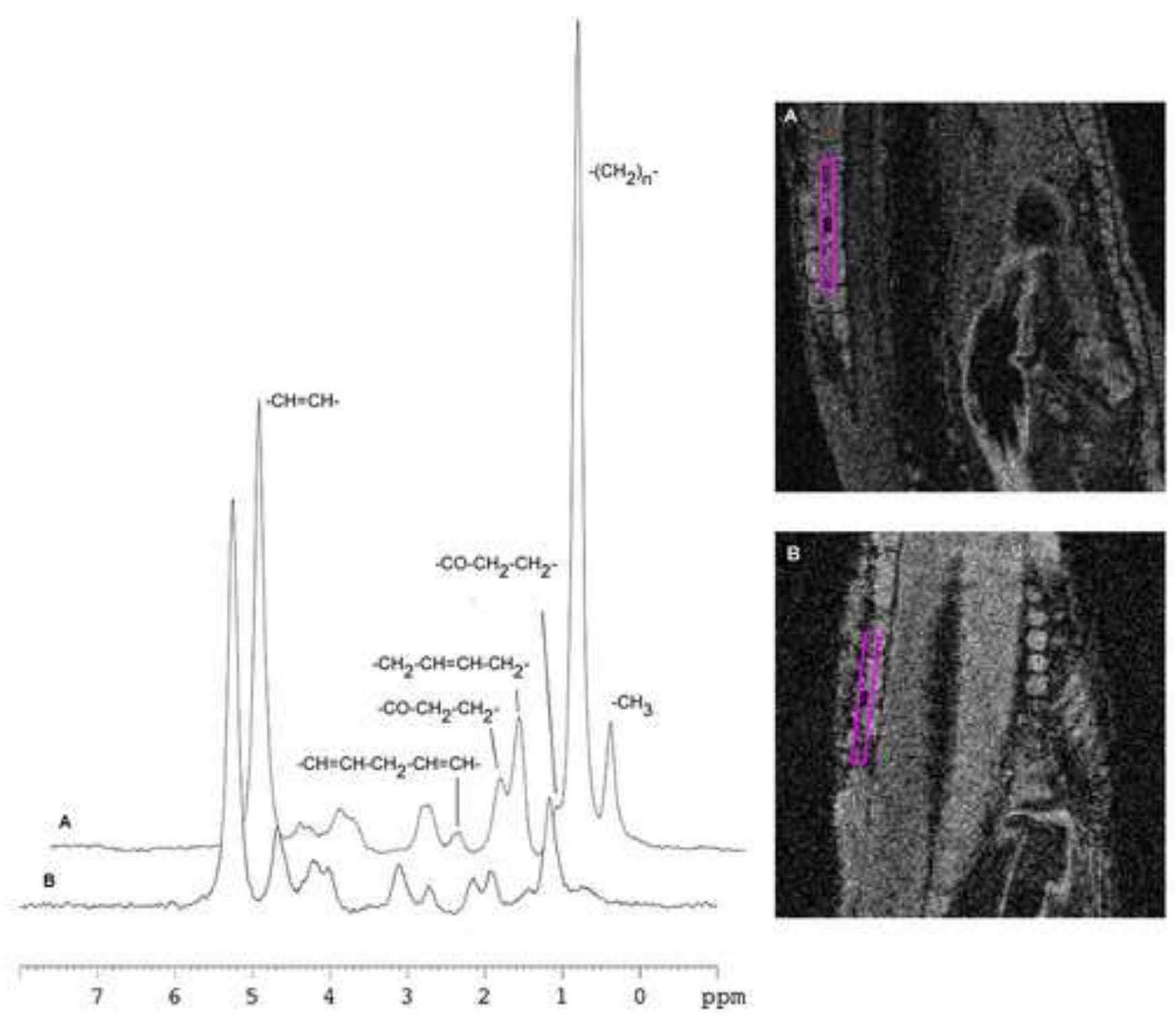

Figure $6 \mathrm{mod}$ 
Table 1: Mean fatty acid (FA) chain length, unsaturation degree and degree of polyunsaturation derived from localized ${ }^{1} \mathrm{H}-\mathrm{NMR}$ spectra measured within the intermuscular lipid sacs of preserved fish from two different sampling locations, Station A (area of the former Larsen A shelf ice) and Station B (former Larsen B shelf ice).* significantly different from Station A, $p<0.05$.

\begin{tabular}{l|ccc} 
& $\begin{array}{c}\text { FA chain } \\
\text { length }\end{array}$ & $\begin{array}{c}\text { Unsaturation } \\
\text { degree }\end{array}$ & $\begin{array}{c}\text { Polyunsaturation } \\
\text { degree }\end{array}$ \\
\hline $\begin{array}{l}\text { Station A } \\
(n=4)\end{array}$ & $7,98 \pm 1,98$ & $3,15 \pm 1,68$ & $1,45 \pm 0,79$ \\
\hline $\begin{array}{l}\text { Station B } \\
(n=5)\end{array}$ & $6,06 \pm 1,14$ & $1,21 \pm 0,79^{*}$ & $0,36 \pm 0,26^{*}$
\end{tabular}

